\title{
REMARKS ON SOME SINGULAR VALUE INEQUALITIES
}

\author{
JIANGUO ZHAO
}

Abstract. In this short note, we present new proofs for some singular value inequalities for matrices obtained by I. Garg and J. Aulja.

Mathematics subject classification (2010): 47A30, 15A60.

Keywords and phrases: Singular values, operator monotone functions, matrix inequalities.

\section{REFERENCES}

[1] J. Aujla And J. Bourin, Eigenvalues inequalities for convex and log-convex functions, Linear Algebra Appl. 424 (2007), 25-35, Springer, New York, 1997.

[2] R. Bhatia, Matrix analysis, Springer-Verlag, New York, 1997.

[3] R. Bhatia, Positive definite matrices, Princeton University press, 2007.

[4] J. Bourin, E. LEe AND M. Lin, Positive matrices partitioned into a small number of Hermitian blocks, Linear Algebra Appl. 438 (2013), 2591-2598.

[5] I. Garg And J. Aujla, Some singular value inequalities, Linear and Multilinear Algebra, doi: 10.1080/03081087.2017.1322035.

[6] S. RoTFEL'D, The singular numbers of the sum of completely continuous operators, Topics Math. Phys. 3 (1969), 73-78.

[7] R. Thompson, Convex and concave functions og singular values of matrix sums, Pacific J. Math. 66 (1976), 285-290.

[8] X. Zhan, Matrix theory, Higher Education Press, In Chinese, 2008. 